\title{
Enamel Solubility and Depth of Demineralization with Laser Bleaching and the Impact of CPP-ACP: An Optico-chemical Analysis
}

\author{
${ }^{1}$ AR Prabhakar, ${ }^{2}$ Sonali Agarwal, ${ }^{3}$ Chandrashekar Yavagal, ${ }^{4} \mathrm{~N}$ Basappa
}

\begin{abstract}
Aim: To determine the enamel solubility and depth of demineralization with laser bleaching and impact of casein phosphopeptide-amorphous calcium phosphate (CPP-ACP) when applied prior to and after laser bleaching.
\end{abstract}

Materials and methods: The 40 specimens obtained from 10 human premolars were treated in accordance with manufacturer protocols; laser bleaching was performed using Opalescence Boost Gel (40\% hydrogen peroxide) followed by laser activation using $36 \mathrm{~mW} / 660 \mathrm{~nm}$ diode laser applied for 4 minutes at an energy fluence of $8.6 \mathrm{~J} / \mathrm{cm}^{2}$.

The study consisted of four experimental groups are as follows:

- Group 1: Control (laser bleaching only)

- Group 2: Pretreatment with CPP-ACP and laser bleaching

- Group 3: Laser bleaching and post-treatment CPP-ACP

- Group 4: Laser bleaching and post-treatment CPP-ACP and short burst of laser.

Specimens were, thereafter, subjected to cariogenic challenge and further evaluated for enamel solubility by measuring the loss of $\mathrm{Ca}^{2+}$ ions and the depth of demineralization using polarized light microscopy.

Results: Group 4 exhibited least enamel solubility and depth of demineralization $(p<0.0001)$ followed by groups 3,2 and maximum by group 1 .

Conclusion: Post-laser bleaching application of CPP-ACP followed by a short burst of laser can provide exceptional resistance to enamel solubility (demineralization).

Keywords: CPP-ACP, Diode laser, Enamel solubility, Enamel demineralization, Laser bleaching, Polarized light microscopy.

How to cite this article: Prabhakar AR, Agarwal S, Yavagal C, Basappa N. Enamel Solubility and Depth of Demineralization with Laser Bleaching and the Impact of CPP-ACP: An Opticochemical Analysis. Int J Laser Dent 2014;4(3):67-73.

Source of support: Nil

Conflict of interest: None

${ }^{1}$ Professor and Head, ${ }^{2}$ Postgraduate, ${ }^{3}$ Reader, ${ }^{4}$ Professor

${ }^{1-4}$ Department of Pedodontics and Preventive Dentistry, Bapuji Dental College and Hospital, Davangere, Karnataka, India

Corresponding Author: AR Prabhakar, Professor and Head Department of Pedodontics and Preventive Dentistry, Bapuji Dental College and Hospital, Davangere, Karnataka, India Phone: 09449602506, e-mail: attiguppeprabhakar@gmail.com

\section{INTRODUCTION}

The dawn of the new millennium has brought about a change in the patients' expectations and perceptions about their dental treatment needs. This increase in demand for dentofacial esthetics is contributing to the development of newer bleaching materials and techniques which are faster, more effective and get completed in one visit (in-office). Bleaching agents (hydrogen peroxide and carbamide peroxide) are used, in combination with different light sources for the removal of stains, intrinsic and extrinsic. ${ }^{1,2}$

Most of these aforementioned techniques use a high concentration bleaching gel $(35-40 \% \mathrm{HP}$ or $30-35 \% \mathrm{CP})$ directly onto the tooth as well as employ an external light source to catalyze/expedite the reaction ultimately leading to a visibly whiter dentition in just a single appointment—a concept that has been popularly termed 'power whitening'. 3,4

The science behind this concept is actually simple wherein the decomposition of hydrogen peroxide results into oxygen and perhydroxyl free radicals, which then oxidize the stained macromolecules and break them down into smaller fragments. These fragments then diffuse across the tooth surface, thereby lightening it thus producing the bleaching effect. To accelerate this reaction, heat, light, and lasers have been used with lasers being the recent yet the most preferred activation method. Berger et al in their study to compare conventional bleaching to laser assisted bleaching concluded that microroughness changes were significantly greater in the conventional office bleaching technique, and hence the laser bleaching could be considered a safer technique. ${ }^{5}$

On the flip side, though the use of these activation methods have shortened the extensive treatment time, their direct contact with bare enamel has the potential to cause some matrix degradation clinically manifesting as sensitivity. ${ }^{5,6}$ This decrease in enamel microhardness $(\mathrm{MH})$, its associated solubility, can be minimized by fluoride and/or casein phosphopeptide-amorphous calcium phosphate (CPP-ACP) application aiming for a potential remineralization after the bleaching procedure. 
But, we do not know whether maximum benefit can be obtained by pre- or post-treatment of teeth with these remineralizing agents.

Hence, the present study is a comparative analysis of the resistance to enamel solubility and demineralization following low level laser-assisted bleaching with pre- and post-treatment of teeth with CPP-ACP.

\section{MATERIALS AND METHODS}

Ethical approval for the study was obtained prior from the Institutional Review Board, Bapuji Dental College, Davangere, Karnataka, India (Ref No: BDC/ Exam/256/2014-15).

Ten human premolars extracted for orthodontic purposes were rinsed in tap water and were cleaned of plaque and debris with a dental handpiece and brush. The buccal, lingual and occlusal surfaces were checked under a stereomicroscope and teeth with enamel defects or cracks were rejected. The selected 10 teeth were stored in $0.9 \%$ saline solution for 1 week and then rinsed in distilled water. Each tooth was sectioned buccolingually or buccopalatinally into two halves with a diamond disc. These halves were then sectioned longitudinally into two parts, so that four specimens were obtained from each tooth, total 40 specimens. These specimens were randomly assigned to one of the four groups' (10 specimens per group), ensuring that each part of every specimen would be in a different group. ${ }^{6}$

All specimens were bleached using Opalescence Boost $40 \%$ (Ultradent Products Inc, South Jordan, USA) that was activated using diode laser unit $660 \mathrm{~nm}$ (Silberbauer, Low Level Laser, Austria). Casein phosphopeptide-amorphous calcium phosphate tooth mousse cream (GC Corp, Tokyo, Japan) was used as the remineralizing agent.

The specimens were randomly assigned into one of the four groups as follows:

- Group 1: Control (only laser bleaching).

- Group 2: Application of CPP-ACP paste followed by laser bleaching.

- Group 3: Laser bleaching followed by application of CPP-ACP paste.

- Group 4: Laser bleaching followed by application of CPP-ACP paste followed by a repeat short burst of laser application.

\section{Methodology}

\section{Group 1}

Opalescence Boost application was done (as per the manufacturers instructions) followed by laser application using $36 \mathrm{~mW} / 660 \mathrm{~nm}$ diode laser (Silberbauer, Low Level Laser, Austria) applied for 4 minutes at an energy fluence of $8.6 \mathrm{~J} / \mathrm{cm}^{2}$.

\section{Group 2}

Casein phosphopeptide-amorphous calcium phosphate application for 5 minutes using a brush (as per the manufacturers instructions). The CPP-ACP paste was then wiped with cotton, followed by Opalescence Boost application (as per the manufacturers' instructions) followed by laser application using $36 \mathrm{~mW} / 660 \mathrm{~nm}$ diode laser (Silberbauer, Low Level Laser, Austria) applied for 4 minutes at an energy fluence of $8.6 \mathrm{~J} / \mathrm{cm}^{2}$.

\section{Group 3}

Opalescence Boost application (as per the manufacturers' instructions) followed by laser application using $36 \mathrm{~mW} / 660 \mathrm{~nm}$ diode laser (Silberbauer, Low Level Laser, Austria) applied for 4 minutes at an energy fluence of $8.6 \mathrm{~J} / \mathrm{cm}^{2}$ followed by single application of CPP-ACP tooth mousse for 5 minutes using a brush (as per the manufacturers instructions). The CPP-ACP was later wiped away with cotton.

\section{Group 4}

Opalescence boost application (as per the manufacturers' instructions) followed by laser application using 36 mW/660 nm diode laser (Silberbauer, Low Level Laser, Austria) applied for 4 minutes at an energy fluence of $8.6 \mathrm{~J} / \mathrm{cm}^{2}$ followed by single application of CPP-ACP tooth mousse for 5 minutes using a brush (as per the manufacturers' instructions) followed by a short burst of laser application for 2 minutes using the same laser as before. The CPP-ACP was later wiped away with cotton. ${ }^{7}$

For the laser activation of the bleaching gel for all the groups, the laser was held at a distance of $1 \mathrm{~mm}$ from the bleaching gel. The bleaching gel was applied to a thickness of 1 to $1.5 \mathrm{~mm}$ and was agitated in between as recommended by the manufacturer.

\section{Analysis of Calcium Loss}

Immediately after the application of the bleaching agents for the prescribed time, the specimens were washed with a water spray and dried with blasts of air. Then, the enamel was covered with wax so as to expose a window area $\left(6 \mathrm{~mm}^{2}\right)$ and placed in acetic acid buffered with $0.34 \mathrm{M}$ sodium acetate $(\mathrm{pH}=4)$ that was used as an artificial caries solution. Salt of calcium monohydrate $\left[\mathrm{Ca}\left(\mathrm{H}_{2} \mathrm{PO}_{4}\right)_{2}\right.$. $\left.\mathrm{H}_{2} \mathrm{O}\right)$ ] was dissolved to obtain $10 \mathrm{mmol} \mathrm{Ca}^{2+}$ and $20 \mathrm{mmol}$ $\mathrm{PO}_{4}{ }^{3-}$ in the solution.

Each specimen was treated with $50 \mathrm{ml}$ of solution in the polyethylene test tubes for 2 hours thrice daily (from 9 am to $9 \mathrm{pm}$ ) for 1 week. In between periods of immersion into demineralizing solution samples were immersed in distilled water $(\mathrm{pH}=7.0)$ for 2 hours. From $9 \mathrm{pm}$ to $9 \mathrm{am}$, teeth were incubated in distilled water. 
Each day, the test tubes were agitated. At the end of 7 days (1 week), solutions were tested for their $\mathrm{Ca}^{2+}$ loss using the flame photometer (Systronics, India). 6,8

\section{Polarized Light Microscopic Analysis}

Slices of thickness $100 \pm 10 \mu \mathrm{m}$ were obtained from the specimens using a hard-tissue microtome (Leica SP 1600, Leica Microsystems Inc, USA). The slices were immersed in distilled and deionized water, mounted on glass slides and the demineralization depth was analyzed in a polarized light microscope (Olympus dual stage, BX-51, Dual Mount Corporation, Minneapolis, Minn). The images were transferred to the computer via digital camera. The lesion depth was measured at three points from the enamel surface using computer software (Image-Pro Plus) and the values were expressed in micrometers $(\mu \mathrm{m})$ to calculate the means. ${ }^{9}$

\section{STATISTICAL ANALYSIS}

The values obtained for calcium ion concentration $(\mu \mathrm{g} / \mathrm{ml})$ and the zones of demineralization $(\mu \mathrm{m})$ were subjected to one way analysis of variance (ANOVA) for multiple group comparison followed by post-hoc Tukey's test for groupwise comparison.

Table 1: Descriptive statistics depicting enamel solubility as assessed by calcium ion concentration $(\mu \mathrm{g} / \mathrm{ml})$

\begin{tabular}{llll}
\hline Groups & $N$ & Mean & SD \\
\hline Group 1 (laser bleaching only) & 10 & 4.90 & 0.64 \\
Group 2 (pre CPP-ACP_laser & 10 & 3.24 & 0.21 \\
bleaching) & & & \\
Group 3 (laser bleaching_post CPP-ACP) & 10 & 2.59 & 0.44 \\
Group 4 (laser bleaching_post CPP- & 10 & 1.27 & 0.17 \\
ACP-laser) & & & \\
\hline Total & 40 & 3.00 & 1.38 \\
\hline ANOVA value (F): 131.44; $\mathrm{p}^{*}$-value < 0.0001; *Highly significant
\end{tabular}

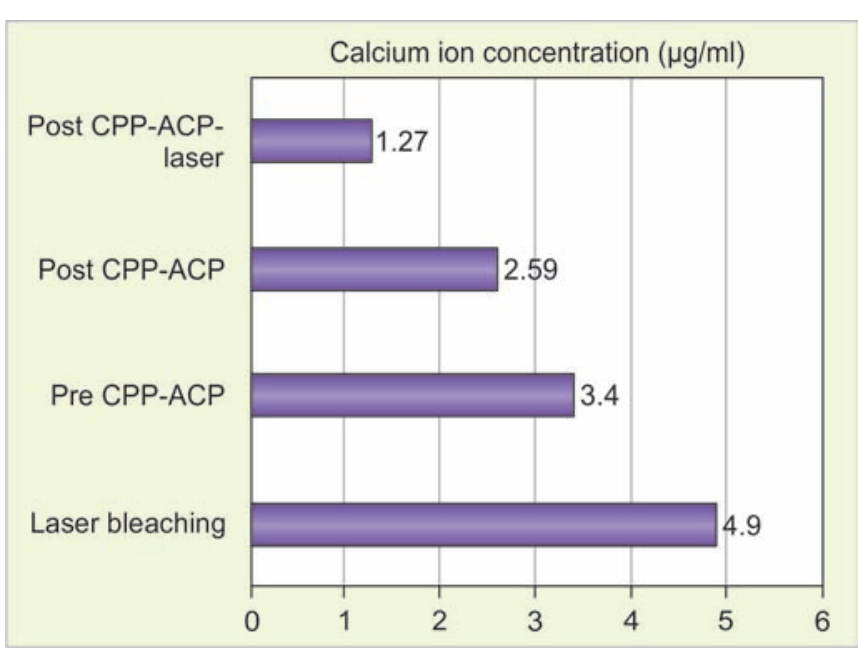

Graph 1: Calcium ion concentration depicting enamel solubility for different groups

\section{RESULTS}

At the end of 1 week, calcium ions released per $\mathrm{mm}^{2}$ for all the groups were calculated cumulatively as shown in Table 1. The demineralization depths for all the samples were determined by PLM (Table 2 and Figs 1A to D).

The highest release of calcium ions was shown by the control group $(4.90 \pm 0.64)$ followed by group 2 (3.24 \pm $0.21)$ then group $3(2.59 \pm 0.44)$ and least by group $4(1.27 \pm$ 0.17) (Table 1 and Graph 1).

Similarly, the highest demineralization depth was shown by control group ( $41.45 \pm 0.63)$ followed by group 2 $(31.38 \pm 0.71)$ followed by group $3(28.75 \pm 0.35)$ and least by group 4 (17.37 \pm 0.70$)$ (Table 2 and Graph 2).

Thus there was a significant difference/effect of different treatments on enamel solubility and depth of demineralization. Accordingly referring to Tables 1 and 2 on descriptive statistics, it can be inferred that teeth exposed to treatment option no. 4, i.e. laser-post CPPACP and laser has least enamel solubility $(1.27 \mu \mathrm{g} / \mathrm{ml})$ and depth of demineralization $(17.37 \pm 0.70)$.

The loss of calcium and depth of demineralization in each of the test groups were compared with that of the control group using the repeated measures ANOVA. A statistically significant difference was observed among the groups $(\mathrm{p}<0.05)$ (Tables 1 and 2$)$.

Table 2: Descriptive statistics showing depth of demineralization $(\mu \mathrm{m})$

\begin{tabular}{|c|c|c|c|}
\hline Groups & $N$ & Mean & $S D$ \\
\hline Group 1 (laser bleaching only) & 10 & 41.45 & 0.63 \\
\hline $\begin{array}{l}\text { Group } 2 \text { (pre CPP-ACP_laser } \\
\text { bleaching) }\end{array}$ & 10 & 31.38 & 0.71 \\
\hline Group 3 (laser bleaching-post CPP-ACP) & 10 & 28.75 & 0.35 \\
\hline $\begin{array}{l}\text { Group } 4 \text { (laser bleaching-post CPP- } \\
\text { ACP-laser) }\end{array}$ & 10 & 17.37 & 0.70 \\
\hline Total & 40 & 29.73 & 8.70 \\
\hline
\end{tabular}

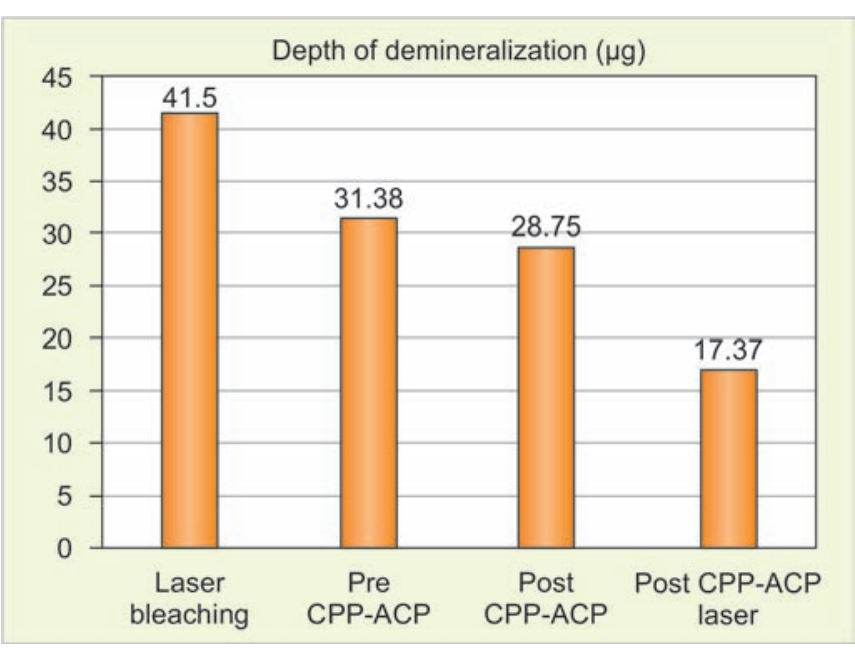

Graph 2: Depth of demineralization $(\mu \mathrm{m})$ for different groups 

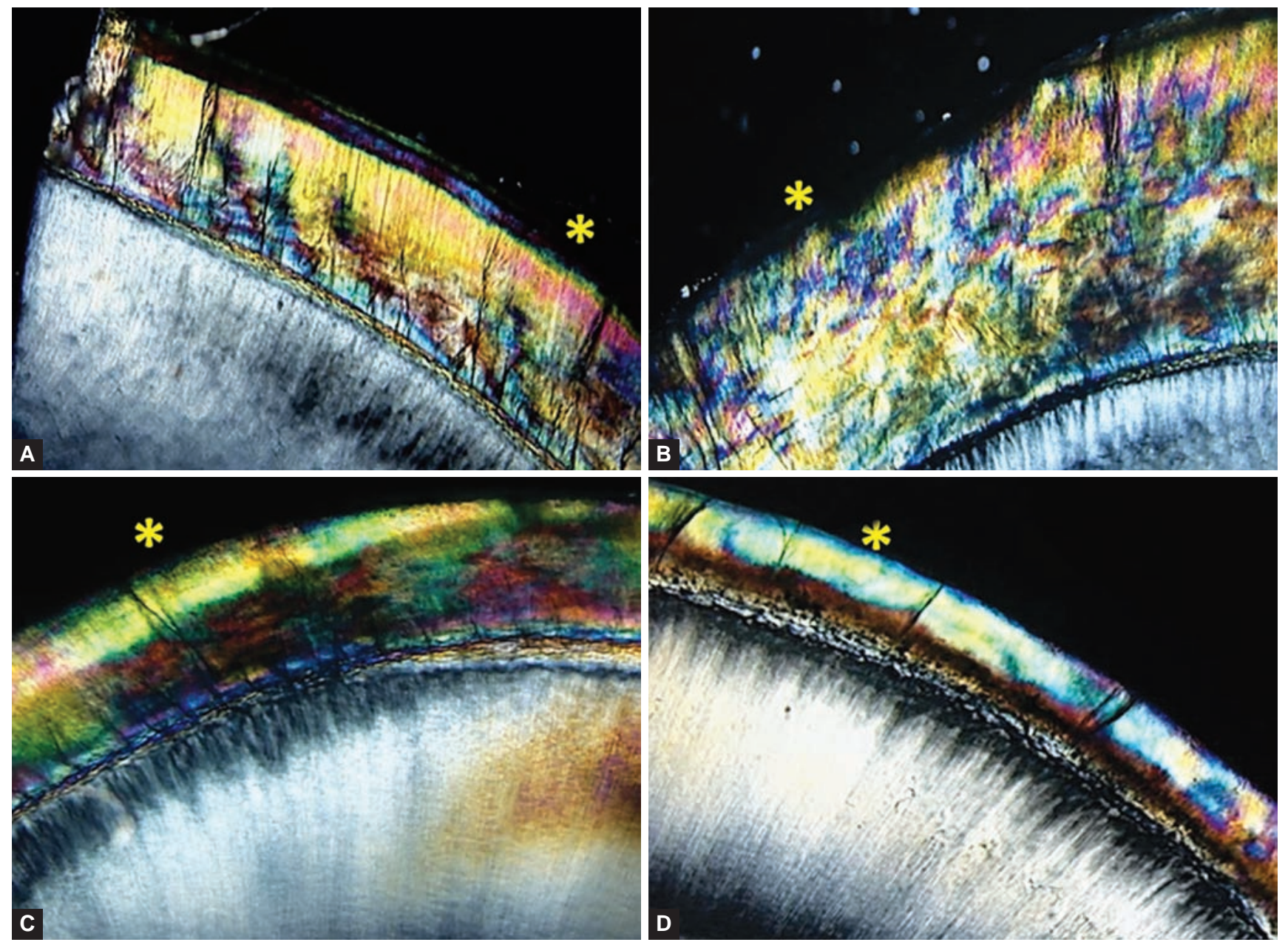

Figs 1A to D: Polarized light microscopy images—representative of one sample from all the groups: Tooth specimens subjected to laser bleaching only (A), pre CPP-ACP followed by laser bleaching (B), laser bleaching followed by post CPP-ACP (C), and laser bleaching followed by post CPP-ACP followed by short burst of laser (D) (*Demineralization zone)

Because the ANOVA test was found to be significant, post-hoc Tukey's test was used to analyze the significance between the groups.

Following application of post-hoc Tukey's test, a significant difference was found among all the groups for both calcium concentration and depth of demineralization.

\section{DISCUSSION}

Bleaching agents cause superficial structural changes in dentin ${ }^{10}$ and enamel, ${ }^{11,12}$ and their low $\mathrm{pH}$ probably produces an effect similar to etching effect, thereby increasing the permeability of dentine. ${ }^{13}$ Concentrated $30 \%$ solutions of hydrogen peroxide can also reduce the microhardness of both enamel and dentin. This reduction can be noted with exposure times as short as 5 minutes for dentin and 15 minutes for enamel. ${ }^{14}$

Studies by scanning electron microscopy (SEM) have shown that even a concentration of $10 \%$ carbamide peroxide, which ultimately breaks down in presence of saliva to $7 \%$ urea and $3 \%$ hydrogen peroxide, ${ }^{15}$ alters enamel, causing surface dissolution and exposing a porous surface. ${ }^{16-19}$
Over the last few years, the 'in-office' bleaching technique has literally been revamped thanks to the availability of high concentration agents which can get activated by a host of light sources, be it halogen, plasma arc, LED or laser. ${ }^{20-24}$

However, the activation of bleaching agents by such thermocatalytic techniques has been questioned because of their potential to cause overheating of the pulpal tissue, thus, increasing the incidence of postoperative sensitivity as well as deleterious effects on enamel. ${ }^{25-28}$

Even lasers that have been used for such thermocatalytic activations have been seen to produce similar tissue damage owing to a significant increase in pulpal temperature. ${ }^{29-30}$

However, the point to be noted, here, is that almost all the previous researchers have employed surgical 'hard' lasers for the activation of bleaching agents typically those belonging to one of the following FDA approved wavelengths-Argon, $\mathrm{CO}_{2}$ and $980 \mathrm{~nm} \mathrm{GaAlAs} \mathrm{diode.} \mathrm{On}$ the contrary, several studies have confirmed the effectiveness of nonsurgical low-level 'soft' lasers for treating the hypersensitivity postbleaching. ${ }^{31-33}$ 
So, it is logical to reason the kind of effect that a low power laser could produce if it were to be used for activation of a bleaching gel, per se. Indeed, Pleffken PR et al precisely tried this and evaluated the efficacy of a $660 \mathrm{~nm}$ low level laser as an activating agent as well as studied its effect on the rise of pulpal temperature. They concluded that a low-power laser increased the efficacy of the bleaching gel with minimum increase in pulpal temperature, much below the deleterious level at which pulpal damage could even be anticipated. Hence, low level laser activation of bleaching gel seems to be an excellent option for providing desired esthetic results with almost zero collateral damage. Hence, we employed a $660 \mathrm{~nm}$ (Silberbauer, Low Level Laser, Austria) laser for this particular intervention. ${ }^{7}$

Even on the economy front, a low power laser seems to score over its high power counterpart. The high power lasers are not only deleteriously thermal but are expensive as well. Low-level lasers are relatively inexpensive, portable and have multiple applications in several branches of dentistry thus making them a win-win proposition for the patient as well as the clinician.

\section{Science behind the Bleaching Process and the Concept of Enamel 'Rebuild'}

The strong oxidizing effect of hydrogen peroxide on the organic matrix of teeth plays a predominant role in the alterations observed in the color of the teeth postbleaching. The low $\mathrm{pH}$ of the bleaching agent, causing subsequent alterations in the mineral composition and decreasing enamel and dentin microhardness are an inseparable aspect of any whitening intervention. ${ }^{34-37}$

However, this decrease in enamel microhardness, and hence solubility can be minimized with the use of fluoride and/or CPP-ACP application, after bleaching, aiming for a potential remineralization provided by these agents.

Borges $\mathrm{BC}$ et al in their research used carbamide peroxides modified by CPP-ACP to study its effect on the microhardness of bleached enamel. They concluded that the use of a CPP-ACP paste with carbamide peroxide bleaching agents increased the bleached enamel's microhardness without delimiting the whitening efficacy. ${ }^{38}$

\section{Choice of the Remineralizing Agent and the Impact of Laser}

Bayrak et al evaluated the effect of CPP-ACP application on the microhardness of bleached enamel in comparison to fluoride. They concluded that with CPP-ACP was statistically more effective than fluoride, hence CPP-ACP was chosen as the remineralizing agent of choice for the present study. ${ }^{39}$
Literature also reports better penetration of these remineralizing agents when used in conjunction with the laser. Studies by Sobral MA et al ${ }^{40}$ and Westerman GH et $\mathrm{al}^{41}$ have proved the same. Our results showed that the combined use of low-power laser with CPP-ACP had the most significant impact as far as calcium dissolution was concerned. This was probably due to the fact that low-power lasers have an iontophoretic effect in driving the calcium and phosphate ions into the enamel matrix. The fact that this very matrix was previously subjected to a demineralization phase, because of the concurrent use of a high concentration bleaching agent, seems to have further enhanced this action.

In a similar study, authors had previously concluded that a low-power red laser could probably entrap $\mathrm{Ca}^{2+}$ and $\mathrm{PO}_{4}{ }^{3-}$ ions during an acidogenic challenge. ${ }^{42}$ Our findings are in accordance to this.

\section{Choice of the Bleaching Agent}

Opalescence Boost $40 \%{ }^{\circledR}$ (Ultradent, South Jordan, Utah, USA), according to manufacturers' instructions, can be used as a standalone agent without needing any external light or laser for its activation. Still, we used it as the bleaching agent of choice as it contains a chromophore in carotene. Though it does not need any exogenous source for its activation, light or laser irradiation nevertheless accelerates the procedure, thereby minimizing the time of exposure of the enamel to a very high concentration of $\mathrm{H}_{2} \mathrm{O}_{2}$, i.e. $40 \%$.

\section{Laser before or after?}

Although previous studies have shown better uptake of remineralizing agents when used in conjunction with laser irradiation there has been a controversy whether maximum benefit can be obtained pre- or post-laser application of these agents.

Most of the authors have found that greater benefit is achieved by post-laser application of the remineralizing agents. ${ }^{43,44}$

Similar, result was obtained in the present study as well wherein post-laser application of CPP-ACP, samples exhibited lesser enamel solubility as determined by the calcium ion concentration in the demineralizing solution as well as decreased zones of demineralization on polarized light microscopic analysis.

The present study is the first study wherein an attempt was made to maximize the diffusibility of calcium and phosphate ions from CPP-ACP by introducing a new group (group 4) wherein post-laser application of CPP$\mathrm{ACP}$, another short burst of laser therapy was provided using the same $660 \mathrm{~nm}$ low-level laser. 
This group was formulated on the assumption that a short burst of laser application following post CPP-ACP application could achieve enhanced permeability of the calcium and phosphate ions as a result of cumulative iontophoretic action as cited before. The results collaborated with our assumption and maximum resistance to enamel solubility and demineralization of enamel was seen in this particular group.

\section{CONCLUSION}

Low-level laser-assisted tooth whitening in conjunction with post-laser CPP-ACP application can provide exceptional resistance to enamel demineralization although further long-term studies are required to establish the strength of this association.

\section{ACKNOWLEDGMENT}

The authors would sincerely like to thank the Staff of Department of Environmental Engineering, Bapuji Institute of Engineering and Technology, Davangere, and Department of Oral Pathology, Bapuji Dental College and Hospital and College of Dental Sciences, Davangere, where the present study parameters were evaluated.

\section{REFERENCES}

1. Haywood VB. Achieveing, maintaining and recovering successful tooth bleaching. J Esthet Dent 1996;8(1):31-38.

2. White JM, Pelino JEP, Rowu R, Nguyen HM. Surface and pulpal temperature comparison of tooth whitening using lasers and curing lights. Proc Soc Photo Opt Instrum Eng 2000;39(10):95-101.

3. Haywood VB. History, safety, and effectiveness of current bleaching techniques and applications of the nightguard vital bleaching technique. Quintessence Int 1992;23(7):471-488.

4. Goldstein RE. In-office bleaching: Where we came from, where we are today. J Am Dent Assoc 1997;128(Suppl):11S-15S.

5. Berger SB, Cavalli V, Ambrosano GM, Giannini M. Changes in surface morphology and mineralization level of human enamel following in-office bleaching with 35\% hydrogen peroxide and light irradiation. Gen Dent 2010 Mar-Apr; 58(2):e74-79.

6. Tezel H, Atalayin C, Erturk O, Karasulu E. Susceptibility of enamel treated with bleaching agents to mineral loss after cariogenic challenge. Int J Dent 2007;38(4):339-347.

7. Pleffken AR, Borges AB, Goncalves SE, Torres CRG. The effectiveness of low-intensity red laser for activating a bleaching gel and its effect in temperature of the bleaching gel and the dental pulp. J Esthet Restor Dent 2012;24:126-134.

8. Giulio AB, Matteo Z, Serena IP, Silvia M, Luigi C. In vitro evaluation of casein phosphopeptide-amorphous calcium phosphate (CPP-ACP) effect on stripped enamel surfaces. A SEM investigation. JD 2009;37(3):228-232.

9. Gabasso SP, Pinto CF, Cavalli V, Paes-Leme AF, Giannini M. Effect of fluoride-containing bleaching agents on bovine enamel microhardness. Braz J Oral Sci 2011;10(1):22-26.
10. Rotstein I, Dankner E, Goldman A, Heling I, Stabholz A, Zalkind M. Histochemical analysis of dental hard tissues following bleaching. J Endodon 1996;22(1):23-26.

11. Bitter NC, Sanders JL. The effect of four bleaching agents on the enamel surface: a scanning electron microscopic study. Quintessence Int 1993;24(11):817-824.

12. Ben-Amar A, Liberman R, Gorfil C, Bernstein Y. Effect of mouthguard bleaching on enamel surface. Am J Dent 1995; 8(1):29-32.

13. Carrasco LD, Forner IC, Corona SA, Pecora JD. Effect of internal bleaching agents on dentinal permeability of nonvital teeth: quantitative assessment. Dent Traumatol 2003; 19(2):85-89.

14. Lewinstein I, Hirschfeld Z, Stabholz A, Rotstein I. Effect of hydrogen peroxide and sodium perborate on the microhardness of human enamel and dentin. J Endod 1994; 20(2):61-63.

15. Marshall MV, Cancro LP, Fischmann SL. Hydrogen peroxide: a review of its use in dentistry. J Periodontol 1995;66(6): 786-796.

16. Bitter NC. A scanning electron microscopic study of the effect of bleaching agents on enamel: a preliminary report. J Prosth Dent 1992;67(6):852-855.

17. Titley KC, Torneck CD, Ruse ND. The effect of concentrated hydrogen peroxide solutions on the surface morphology of human tooth enamel. J Endod 1988;14(1):69-74.

18. Nathanson D, Parra C. Bleaching vital teeth: a review and clinical study. Compend Contin Educ Dent 1987;8(7):490-498.

19. Hanks CT, Fat JC, Wataha JC, Corcoran JF. Cytotoxicity and dentin permeability of carbamide peroxide and hydrogen peroxide vital bleaching materials, in vitro. J Dent Res 1993; 72(5):931-938.

20. Torres $\mathrm{CRG}$, Borges $\mathrm{AB}, \mathrm{Kubo} \mathrm{CH}$, et al. Bleaching teeth with hybrid LED/laser devices. Sao Paulo: Editora Santos; 2007. p. 140. (In Portuguese.).

21. Kwon YH, Huo MS, Kim KH, et al. Effects of hydrogen peroxide on the light reflectance and morphology of bovine enamel. J Oral Rehabil 2002;29(5):473-477.

22. Sulieman M, Addy M, Macdonald E, Rees JS. A safety study in vitro for the effects of an in-office bleaching system on the integrity of enamel and dentine. J Dent 2004;32(7):581-590.

23. Sulieman M, Addy M, Macdonald E, Rees JS. The bleaching depth of a 35\% hydrogen peroxide based in-office product: a study in vitro. J Dent 2005;33(1):33-40.

24. Lima DA, Aguiar FH, Liporoni PC, et al. In vitro evaluation of the effectiveness of bleaching agents activated by different light sources. J Prosthodont 2009;18(3):249-254.

25. Carrasco TG, Carrasco-Guerisoli LD, Froner IC. In vitro study of the pulp chamber temperature rise during light-activated bleaching. J Appl Oral Sci 2008;16(5):355-359.

26. Papathanasiou A, Kastali S, Perry RD, Kugel G. Clinical evaluation of a $35 \%$ hydrogen peroxide in-office whitening system. Compend Contin Educ Dent 2002;23(4):335-358, 40, 43-44 passim; quiz 48.

27. Eldeniz AU, Usumez A, Usumez S, Ozturk N. Pulpal temperature rise during light-activated bleaching. J Biomed Mater Res B Appl Biomater 2005;72(2):254-259.

28. Buchalla W, Attin T. External bleaching therapy with activation by heat, light or laser-a systematic review. Dent Mater 2007;23(5):586-596.

29. Baik JW, Rueggeberg FA, Liewehr FR. Effect of light-enhanced bleaching on in vitro surface and intrapulpal temperature rise. J Esthet Restor Dent 2001;13(6):370-378. 
30. Michida, de Araujo SM, et al. Intrapulpal temperature variation during bleaching with various activation mechanisms. J Appl Oral Sci [online]. 2009;17(5):436-439.

31. Gerschman JA, Ruben J, Gebart-Eaglemont J. Low-level laser therapy for dentinal tooth hypersensitivity. Aust Dent 1994 Dec;39(6):353-357.

32. Dantas $\mathrm{CMG}$, et al. In vitro effect of low intensity laser on the cytotoxicity produced by substances released by bleaching gel. Braz Oral Res 2010;24(4):460-466.

33. Etemadi A, Sadeghi M, Dadjou MH. The effects of low level $660 \mathrm{~nm}$ laser irradiation on pain and teeth hypersensitivity after periodontal surgery. J Lasers in Medical Sciences 2011;2(3):103-108.

34. Pinto CF, Oliveira R, Cavalli V, Giannini M. Peroxide bleaching agent effects on enamel surface microhardness, roughness and morphology. Braz Oral Res 2004;18(4):306-311.

35. Seghi RR, Denry I. Effects of external bleaching on indentation and abrasion characteristics of human enamel in vitro. J Dent Res 1992;71(6):1340-1344.

36. Hegedüs C, Bistey T, Flóra-Nagy E, Keszthelyi G, Jenei A. An atomic force microscopy study on the effect of bleaching agents on enamel surface. J Dent 1999;27(7):509-515.

37. Chng HK, Ramli HN, Yap AUJ, Lim CT. Effect of hydrogen peroxide on intertubular dentine. J Dent 2005;33(5):363-369.

38. Borges BC, Borges JS, de Melo CD, Pinheiro IV, Santos AJ, Braz R, Montes MA. Efficacy of a novel at-home bleaching technique with carbamide peroxides modified by CPP-ACP and its effect on the microhardness of bleached enamel. Oper Dent 2011 Sep-Oct;36(5):521-528.

39. Bayrak S, Tunc ES, Sonmez IS, Egilmez T, Ozmen B. Effects of casein phosphopeptide-amorphous calcium phosphate (CPPACP) application on enamel microhardness after bleaching. Am J Dent 2009 Dec;22(6):393-396.

40. Sobral MA, Lachowski KM, de Rossi W, Braga SR, Ramalho KM. Effect of Nd: YAG laser and acidulated phosphate fluoride on bovine and human enamel submitted to erosion/ abrasion or erosion only: an in vitro preliminary study. Photomed Laser Surg 2009 Oct;27(5):709-713.

41. Westerman GH, Ellis RW, Latta MA, Powell GL. An in vitro study of enamel surface microhardness following argon laser irradiation and acidulated phosphate fluoride treatment. Pediatr Dent 2003 Sep-Oct;25(5):497-500.

42. Vlacic, IA Meyers, LJ Walsh. Laser-activated fluoride treatment of enamel as prevention against erosion. Aust Dent J 2007;52:(3):175-180.

43. Khamaal I. AL-Hasnawi, Wesal A. Al-Obaidi. Effect of NdYAG laser-irradiation on fluoride uptake by tooth enamel surface (in vitro). J Orthodontics, Pedodontics and Preventive Dentistry March 2014;26(1):154-158.

44. Tagomori S, Morioka T. Combined effects of laser and fluoride on acid resistance of human dental enamel. Caries Res 1989;23(4):225-231. 